\title{
Averting Expenditure and the Cost of Pollution
}

\author{
Paul N. Courant \\ Department of Economics and Institute of Public Policy Studies, \\ The University of Michigan, Ann Arbor, Michigan 48109 \\ AND \\ RICHARD C. PORTER \\ Department of Economics, The University of Michigan, \\ Ann Arbor, Michigan 48109 \\ Received June 1, 1979; revised February 1, 1981
}

\begin{abstract}
The paper considers the relationship between the willingness to pay for environmental quality and averting expenditures - that is, the costs of measures undertaken in efforts to counteract the consequences of pollution. The models used assume perfect mobility among locations with different levels of environmental quality. The major results are: (1) $\Lambda$ verting expenditures are not in general a good measure of willingness to pay; (2) averting expenditures are not always even a lower bound on willingness to pay; (3) even when averting expenditures are a lower bound, the difference between the level of such expenditures and willingness to pay cannot be attributed to the unavertible "aesthetic" consequences of pollution.
\end{abstract}

For almost every kind of environmental unpleasantness we face, there are averting expenditures we can make to reduce, and sometimes completely remove, the damage. For air pollution, house paint, air conditioners, soap; for water pollution, wells, bottled water, purifiers; for noise pollution, storm windows, thicker walls. Economists have long been aware that averting behavior is both possible and practiced, and they have often suggested that expenditures on such behavior can be used as a measure of the costs imposed on society by various forms of pollution. The literature on this subject is difficult to characterize, but to the extent that a consensus has been reached, it is that averting expenditures provide a lower bound estimate of the total costs imposed by pollution, and the divergence between averting expenditures and the total costs of pollution arises from the fact that some consequences of pollution (e.g., the simple unpleasantness of breathing dirty air) cannot be averted. ${ }^{2,3}$

In this note we develop two simple models of the response of utility maximizing consumers to small changes in the level of pollution which they face. In the first model, we assume that environmental quality is desired solely because it reduces the need for averting expenditure; we show that: (1) the level of averting expenditure may be either a lower bound or an upper bound estimate of the consumer's

\footnotetext{
'We are grateful to T. C. Bergstrom, D. L. Rubinfeld, H. R. Varian, and the referees for comments on earlier drafts.

${ }^{2}$ See, for example, $[13$, p. $91 ; 5$, p. $127 ; 4$, p. $77 ; 1$, p. $178 ; 7$, p. $32 ; 14$, p. 175, Appendix B; 9, p. 146].

${ }^{3}$ There is another literature, exemplified by the work of K.-G. Mäler, [10, pp. 106-118], which considers expenditures on private goods made in order to abet the benefits of a public environmental good. Although the analysis is formally similar, we prefer to stress averting expenditure because few people believe abetting expenditures to be a good measure of willingness to pay for public environmental goods (see, for example, [8, p. 454]).
} 
willingness to pay for less pollution, depending on the properties of the technology under which averting expenditure achieves its purpose; and (2) there is no assurance that averting expenditure will be a good approximation of willingness to pay. In the second model, we go on to consider a case where environmental quality directly affects consumer well-being, and hence where some of the costs of pollution cannot be averted through private expenditure; we show that knowledge of the production function for averting behavior is no longer sufficient to determine whether the level of averting expenditure is an upper bound or lower bound estimate of willingness to pay. Then, specific information on the properties of the utility function as well as the production function is required if we are to use the averting expenditure to put bounds on the willingness to pay.

\section{THE FIRST MODEL}

For simplicity, we consider a world in which there is only one environmental amenity, air quality $(A)$, and one kind of averting behavior, the use of soap $(S)$. The private good, soap, and the public good, air quality, together produce cleanliness $(C)$ by means of a known technology, concave and increasing in each argument,

$$
C=C(S, A) .
$$

Otherwise identical consumers face different air qualities in different locations and maximize utility by allocation of personal income $(Y)$ between the purchase of soap and a composite consumption good $(X)$. (Units of both soap and the consumption good are chosen so that they have prices of unity.) In this first model, pollution affects utility only through its effect on the cost of cleanliness; air quality does not enter directly into the utility function, and the utility function is given by

$$
U=U(C, X)
$$

where (2) is increasing in each argument. ${ }^{4}$

It is assumed that all locations are open to migration. This assumption and the assumption that all consumers are identical imply that the level of utility achieved must be the same in all locations when the system is in equilibrium. In more complicated models (e.g., Polinsky and Rubinfeld, [11]), migration would assure that the advantages of locations with cleaner air would be compensated for by differences in prices, incomes, property values, and/or congestion. In our simple models, all of these forces are proxied by differences in income. The willingness to pay for marginal improvement in the level of air quality $(d A>0)$ is defined as the decline in income $(d Y)$ that would leave utility constant.

We start with the simple case where the production function for cleanliness is such that the marginal product of soap is increasing in air quality but constant for a given air quality $\left(C_{S A}>0\right.$ and $C_{S S}=0$, where the subscripts indicatc second partial derivatives). In this case, the cost of a unit of cleanliness depends only on $A$, and at

\footnotetext{
${ }^{4}$ The assumptions made about (1) and (2) imply that any level of $C$ can be achieved at any level of $A$. In this sense, all consequences of pollution are "avertible." The case where some consequences of pollution are not avertible is dealt with in the second model, in the next section. There, the utility function will be given by $U=U(C, X, A)$.
} 
any given level of $A$ a consumer may buy cleanliness at constant cost, $P(A)$. Since the consumer is maximizing utility subject to a budget constraint and parametric prices, the maximization problem may be analyzed by looking at the indirect utility function, ${ }^{5}$

$$
V=V(Y, P(A))
$$

Now we consider the effect of a marginal change in air quality on such a consumer. ${ }^{6}$ The condition for locational equilibrium requires that

$$
\frac{d V}{d A}=\frac{\partial V}{\partial Y} \frac{d Y}{d A}+\frac{\partial V}{\partial P} \frac{d P}{d A}=0
$$

Thus,

$$
\frac{d Y}{d A}=-\frac{\partial V / \partial P}{\partial V / \partial Y} \cdot \frac{d P}{d A}
$$

By a well-known property of the indirect utility function, we know that

$$
-\frac{\partial V / \partial P}{\partial V / \partial Y}=C
$$

and hence that

$$
\frac{d Y}{d A}=C \frac{d P}{d A}
$$

In words, the improvement in air quality lowers the price of cleanliness, and thereby lowers the cost of buying the consumer's previously chosen level of cleanliness. This cost is reduced by the amount, $C(d P / d A)$, the right side of Eq. (7). After migration has restored the equality of utility among cities, income must have fallen by exactly this reduced cost. This income decline is precisely the measure of the consumer's willingness to pay for the improved air quality defined above, since it is that decline which just equalizes utility among cities of different air qualities. Thus, the benefit of a marginal reduction in air pollution (the willingness to pay) is correctly measured by the reduction in the expenditure the consumer would have to make to achieve the same level of cleanliness as he achieved before.

The observed change in the consumer's expenditure on averting behavior is not the same thing, since the amount of cleanliness purchased will increase in response to the lower price. The averting expenditure $(E)$ equals $P \cdot C$, and its change in response to a change in air quality is

$$
\frac{d E}{d A}=P \frac{d C}{d A}+C \frac{d P}{d A}
$$

\footnotetext{
${ }^{5}$ See $[15]$.

${ }^{6}$ More precisely, we consider the effect of a consumer's costless move to a different location with a slightly different air quality. We assume that the distribution by air quality of locations, or "cities," is given and unchanging. Were air quality to change in any one location, there would be a small change in the uniform level of utility by all consumers. See [3] for a discussion of how the uniform level of utility changes in response to a change in conditions in one location.
} 


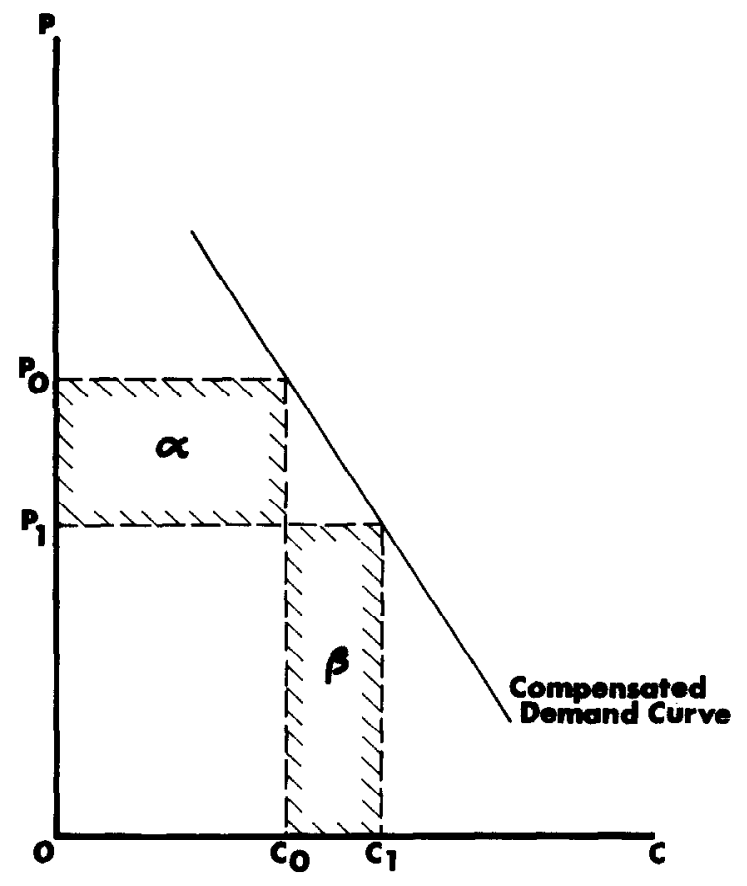

FIGURE 1

Note that there are two terms on the right side of (8), the latter of which is equal, in absolute value, to the consumer's willingness to pay for the improvement in air quality. The absolute value of the change in averting expenditure $(-d E / d A$ in Eq. (8)) will be larger or smaller than the willingness to pay $(-d Y / d A$ in Eq. (7)) according as $d C / d A$ is less than or greater than zero. But an improvement in air quality means a reduced price of cleanliness (i.e., $d P / d A<0$ ); since migration ensures that the consumer moves along the compensated demand curve (i.e., $d U / d A=0$ ), the lower price must induce the purchase of an increased quantity (i.e, $d C / d A>0$ ). Therefore, the change in averting expenditure is an underestimate of the willingness to pay when air quality improves. ${ }^{7}$

While the preceding applies exactly only for marginal changes, its implications for nonmarginal changes can be seen diagrammatically. In Fig. 1 is drawn the compensated demand curve for cleanliness of each of the consumers. If air quality is poor $\left(A_{0}<A_{1}\right)$, the price of cleanliness is high $\left(P_{0}>P_{1}\right)$ and less is purchased $\left(C_{0}<C_{1}\right)$. If the consumer suffering $A_{0}$ could move to $A_{1}$, that consumer would be willing to pay (according to Eq. (7)) an amount equal to the area marked $\alpha$. But if such a locational change were made, we would observe a reduction in averting expenditure of the area, $\alpha-\beta$, which could be positive or negative depending on the price elasticity of the demand curve. The people in the cleaner environment may actually spend more on cleanliness, even with identical tastes and utility. There may not even be a reduction in averting expenditure, but if there is a reduction (i.e., if $\beta<\alpha$ ), then it will be less than the willingness to pay (i.e., $\alpha-\beta<\alpha$ ).

${ }^{7}$ Or, what comes to the same thing, the difference in averting expenditure between two differently located but otherwise identical persons is an underestimate of what the person located in the dirtier environment would be willing to pay to move to the cleaner location. 
Thus, if the production function is such that $C_{S A}>0$ and $C_{S S}=0$, averting expenditures provide a lower bound estimate of the willingness to pay. But if the demand for cleanliness is not very price-inelastic, the estimate will be a poor one; indeed, if the demand for cleanliness is price-elastic, the estimate will be of the wrong sign.

Moreover, the fact that averting expenditure yields a lower bound estimate to the willingness to pay is in no way attributable to neglect of any unavertible or "aesthetic" costs of a poor environment. Environment per se does not enter the consumer's assumed utility function. ${ }^{8}$ Nevertheless, the expenditure change is an underestimate of willingness to pay.

We will now show that the results established above hold whenever $C_{S A}$ is positive, provided that $C_{S S}$ is nonpositive. In general, the consumer maximizes (2) subject to (1) and the budget constraint $(Y=X+S)$. This yields the following first- and second-order conditions:

$$
\begin{gathered}
-U_{X}+U_{C} \cdot C_{S}=0 \\
U_{X X}-2 C_{S} \cdot U_{X C}+C_{S}^{2} \cdot U_{C C}+C_{S S} \cdot U_{C}=\Delta<0,
\end{gathered}
$$

where subscripts represent first and second partial derivatives. An improvement in air quality affects utility as follows:

$$
\frac{d U}{d A}=U_{X} \frac{d Y}{d A}+\left(-U_{X}+U_{C} \cdot C_{S}\right) \frac{d S}{d A}+U_{C} \cdot C_{A}
$$

The second term on the right side becomes zero again after the consumer adjusts his consumption pattern according to (9); and $d U / d A$ becomes zero after migration has eliminated the utility gain from the air improvement. Income must decline:

$$
\frac{d Y}{d A}=-\frac{C_{A}}{C_{S}}<0
$$

The willingness to pay for the improvement is therefore $C_{A} / C_{S}$, and thus depends only on the technology by which the consequences of pollution are averted. Note that it does not depend at all on tastes (i.e., the utility function). This means that if environmental quality does not appear directly in the utility function, one could in principle estimate willingness to pay from an estimate of the relevant production function.

The change in averting expenditure is $d S / d A$, which is readily found by totally differentiating (9) and substituting (12) for $d Y / d A$ :

$$
\frac{d S}{d A}=-\frac{C_{A}}{C_{S}}+\frac{\left(C_{S} \cdot C_{S A}-C_{A} \cdot C_{S S}\right) U_{C}}{-C_{S} \cdot \Delta}
$$

The reduction in averting expenditure is simply the negative of (13).

The decline in the averting expenditure is an overestimate or underestimate of the willingness to pay according as

$$
C_{S} \cdot C_{S A}-C_{A} \cdot C_{S S}
$$

${ }^{x}$ Recall that $U=U(C, X) ; A$ does not enter. 


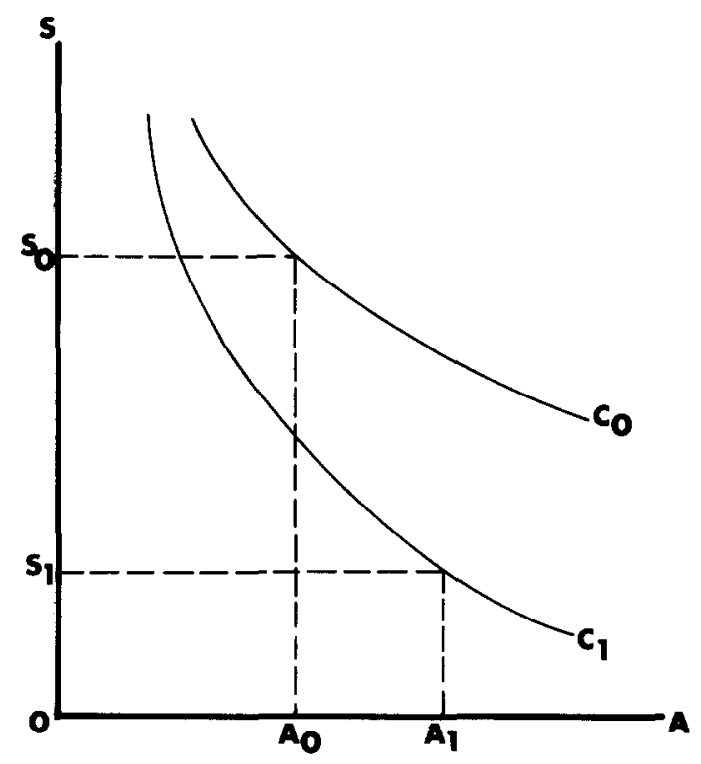

FIGURE 2

is less than or greater than zero. Normally we expect (14) to be positive: $C_{S S}$ is nonpositive if there are nonincreasing returns to soap, and most simple production functions imply a positive cross-partial-derivative $\left(C_{S A}\right)$. If the expression is positive, then the reduction in soap expenditure does provide a lower bound estimate of the willingness to pay, and all of the results established above still hold. Note that the sign of $C_{S A}$ has a straightforward economic interpretation. $C_{S A}$ is positive (negative) if the marginal product of soap in producing cleanliness is increasing (decreasing) with air quality.

While the lower bound result and the analysis associated with Fig. 1 will be correct for any concave production function provided that $C_{S A}$ is positive, there is nothing in neoclassical production theory to rule out the possibility that $C_{S A}$ is sufficiently negative that (14) is negative. ${ }^{9}$ Equation (14) will be negative when the isocleanliness curves are ever flatter as $C$ and $S$ increase, with $A$ being held constant. Further, negativity of (14) implies that maximizing consumers will consume less cleanliness (and more $X$ ) as air quality increases:

$$
\frac{d C}{d A}=C_{S} \frac{d S}{d A}+C_{A}
$$

and, substituting from (13),

$$
\frac{d C}{d A}=\frac{C_{S} \cdot C_{S A}-C_{A} \cdot C_{S S}}{-\Delta} \cdot U_{C}
$$

Such a situation is illustrated in Fig. 2. An increase in air quality, from $A_{0}$ to $A_{1}$, causes in the end a decrease in both soap expenditure and cleanliness, from $S_{0}$ to $S_{1}$

\footnotetext{
${ }^{9}$ Quick examination shows that this possibility is not precluded by the second order condition (10). Indeed, (14) will be negative if $A$ is an "inferior" factor of production (see [2]).
} 
and from $C_{0}$ to $C_{1}$, respectively. In such a case, the change in soap expenditure, $S_{0}-S_{1}$, overstates the willingness to pay for the improved air quality.

Although Fig. 2 may be unfamiliar, it is not hard to think of realistic examples where, between two people who differ only with respect to their environmental quality, the one with the less desired environment achieves a higher level of cleanliness as a result of extensive averting activities. As the air becomes worse, cleaning and painting may become much more intensive; as the water becomes more impure, much more elaborate purification systems may be adopted; as litter grows in unsightliness, much more frequent pickup may be arranged. ${ }^{10}$ In each case, the person whose environment was worse to begin with may well achieve greater "cleanliness" after the averting activities are adopted. And if this occurs, the change in averting expenditure will provide an upper bound rather than a lower bound estimate of willingness to pay. ${ }^{11}$

\section{AIR QUALITY IN THE UTILITY FUNCTION}

Thus far, the analysis has applied to cases where all welfare consequences of pollution are indirect. We now show that if air quality enters the utility function directly, then averting expenditure provides an even less clear estimate of willingness to pay, and not necessarily a lower bound even in the case where the indirect utility function is an appropriate tool. ${ }^{12}$ Let $U=U(C, X, A)$; the indirect utility function becomes $V=V(Y, P, A)$. A change in air quality, in a system of open cities, yields

$$
\frac{d V}{d A}=\frac{\partial V}{\partial Y} \cdot \frac{d Y}{d A}+\frac{\partial V}{\partial P} \cdot \frac{d P}{d A}+\frac{\partial V}{\partial A}=0
$$

The willingness to pay - i.e., absolute value of the observed income change-is

$$
-\frac{d Y}{d A}=-C \frac{d P}{d A}+\frac{\partial V / \partial A}{\partial V / \partial Y}
$$

There are now two elements to the willingness to pay. The first, as before, is that the existing level of cleanliness can be more cheaply achieved (i.e., the first term on the right side of (18)); and the second, a new term, is that air quality directly affects well-being (i.e., the second term on the right side of (18)). Comparison of Eqs. (8) and (18) shows that the reduction in averting expenditure ${ }^{13}$ (i.e., $-d E / d A$ ) is greater or less than the willingness to pay (i.e., $-d Y / d A$ ) according as

$$
0 \gtrless \frac{\partial V / \partial A}{\partial V / \partial Y}+P \frac{d C}{d A}
$$

\footnotetext{
${ }^{10}$ On the optimal rate of litter pickup, and its relation to the rate and volume of litter, see [12, Appendix 2].

${ }^{11}$ Whether this possibility is important in fact is difficult to say. The sparse evidence on averting activities is summarized in $[4, \mathrm{pp} .44-50]$.

${ }^{12}$ That is, where $C_{S S}=0$.

${ }^{13}$ If any; recall that $d E / d A$ might increase.
} 
The first term on the right side of inequality (19) is surely positive, but the sign of the second term depends on the complementarity-substitutability relationships among the three elements of the utility function-i.e., among cleanliness $(C)$, air quality $(A)$, and other goods $(X)$.

Thus, we see that two new problems emerge as a result of considering air quality as a direct influence on well-being: (1) there are now two elements (rather than, as before, one) of divergence between the change in averting expenditure and the willingness to pay, making it even less clear in what sense one is an estimate of the other; and (2) it is no longer certain that the change in averting expenditure provides a lower bound estimate of willingness to pay even with a very simple cleanliness production function. With more complicated production functions, the addition of $A$ itself (or some unavertible consequence of $A$ ) in the utility function will again add to the inappropriateness of using averting expenditure as a measure of willingness to pay. Information on both the properties of the production function and the complementarity-substitutability relationships of the utility function are required to determine whether averting expenditure even bounds willingness to pay. There is still no reason to believe it to be a good estimate.

\section{CONCLUDING REMARKS}

The conclusions of all this are negative. Between two differently located but otherwise identical individuals, the difference in their averting expenditures may or may not be a close estimate of their willingness to pay for the preferred location. It may or may not be a lower bound estimate; it may even be an upper bound estimate. In a rare excursion beyond preneocolonialism, Kipling asserted the principal result (although without proof): "An' it all goes into the laundry, but it never comes out in the wash,...."

\section{REFERENCES}

1. R. U. Ayres, Air pollution in cities, Natur. Resources $J$. (Jan. 1969), as reprinted in (A. F. Schrieber et al., Eds.) "Economics of Urban Problems" Houghton Mifflin, Boston (1975).

2. D. V. T. Bear, Inferior inputs and the theory of the firm, J. Pol. Econ. (June 1965).

3. P. N. Courant and D. L. Rubinfeld, On the measurement of benefits in an urban context: Some general equilibrium issues, $J$. Urban Econ. 5, 346-356 (July 1978).

4. D. N. Dewees, C. K. Everson, and W. A. Sims, "Economic Analysis of Environmental Policies," Univ. of Toronto Press, Toronto (1975).

5. A. M. Frceman, III, R. H. Haveman, and A. V. Kneese, "The Economics of Environmental Policy," Wiley, New York, (1973).

6. R. Kipling, "Stellenbosch."

7. A. V. Kneese, Air pollution-General background and some economic aspects, in "The Economics of Air Pollution", (H. Wolozin, Ed.), Norton, New York (1966).

8. J. L. Knetsch and R. K. Davis, Comparisons of methods for recreation evaluation, as reprinted in "Economics of the Environment" (R. and N. S. Dorfman, Eds.), Norton, New York (1977).

9. E. S. Mills, "The Economics of Environmental Quality," Norton, New York (1978).

10. K.-G. Mäler, A method of estimating social benefits from pollution control, in "The Economics of the Environment" (P. Bohm and A. V. Kneese, Eds.) Macmillan, New York (1971).

11. A. M. Polinsky and D. L. Rubinfeld, The long-run effects of a residential property tax and local public services, J. Urban Econ. 5, 241-262 (April 1978).

12. R. C. Porter, A social benefit-cost analysis of mandatory deposits on beverage containers, J. Environ. Econ. Manag. 5, 351-375 (December 1978). 
13. R. G. Ridker, Strategies for measuring the cost of air pollution, in "The Economics of Air Pollution" (H. Wolozin, ed.) Norton, New York (1966).

14. J. J. Seneca and M. K. Taussig, "Environmental Economics," second edition, Prentice-Hall, Engelwood Cliffs, N. J. (1979).

15. H. Varian, "Microeconomic Analysis," Norton, New York (1979).

16. R. Zeckhauser and A. Fisher, "Averting Behavior and External Diseconomies," Discussion Paper 4ID, J. F. Kennedy School of Government, Harvard University (April 1976). 